\title{
Leitores Relutantes e Práticas Escolares de Leitura Juvenil: aprendendo o prazer de ler, com Harry Potter
}

\section{Relutant readers and school reading practices: learning the pleasure of reading with Harry Potter}

\author{
Marta Campos de Quadros* \\ Renata JungueiRa de SOUZ*** \\ ZIZI TREVIZAN***
}

Resumo: Esse artigo discute a inserção da escola no âmbito das culturas juvenis, estimulando-a a articular leitura, tecnologias, mídia e conectividade. Utilizando-se de pesquisa bibliográfica e de resultados obtidos em uma investigação (Quadros, 2011), as autoras efetuam o percurso característico do leitor, que pode se identificar, no processo inicial de formação, com o perfil do leitor relutante (Jobe e Sakari, 1999), mas que gradualmente, por meio de práticas escolares, se apropria culturalmente do poder e do controle da leitura. Os resultados apontam para a responsabilidade social da escola, na construção histórico-cultural do perfil e do repertório de seus jovens leitores.

Abstract: This paper examines the role that schools can play in youth cultures, encouraging the educational system to articulate reading, technologies, media and connectivity. Through bibliographical research and outcomes from investigation (QUADROS, 2011), we outline that the reader's initial path can meet, in early education, with the concept of reluctant reader (itálicos nestas duas últimas palavras) (JOBE \& SAKARI, 1999). Through educational practices, readers may gradually take cultural control of the reading process. The outcomes point out to the schools' social responsibility regarding to the building of the young readers' repertoire and cultural profile.

Palavras-chave: Literatura Juvenil, Práticas de Leitura Leitores Relutantes.

Keywords: Literature for youngsters, Reading Practices, Reluctant Readers.

\footnotetext{
* Doutora em Educação pela UFRGS, RS. Atualmente é bolsista do PBPD/Capes na Unesp de Presidente Prudente, SP.

** Doutora em Letras pela Unesp de Assis. Professora do Programa de Mestrado e Doutorado em Educação da Unesp, Presidente Prudente, SP. Coordenadora do CELLIJ - Centro de Estudos em Leitura e Literatura Infantil e Juvenil.

*** Doutora em Letras pela Unesp de Assis. Professora do Programa de Mestrado em Educação da Unoeste, Presidente Prudente, SP.
} 
Tá ligado?! - os jovens e algumas questões sobre leitura

É comum verificarmos jovens plugados a artefatos portáteis de comunicação como $\mathrm{mp} 3$ e telefones multifuncionais. Atualmente, tais aparelhos fazem parte da indumentária destes garotos, seja em parques, shoppings, escolas, transporte urbano, templos religiosos, etc. Neste contexto, a conectividade anunciada cotidianamente por meio da expressão - Tá ligado?! - adquiriu, em nossa sociedade, densidade como marcador identitário (Martín-Barbero, 2004) de uma determinada juventude urbana, ao mesmo tempo em que foi sendo intensamente utilizada nas narrativas midiáticas para caracterizar esta mesma juventude.

Estar ligado para muitos jovens é o mesmo que estar no mundo, conectado às múltiplas redes não apenas no sentido técnico, mas no sentido de fazer parte de um (ou mais de um) grupo, de compartilhar práticas e ideias. Nesta direção, Hall $(1997)^{1}$ pondera que todas as práticas sociais expressam ou comunicam significados construídos em múltiplas relações com o nosso entorno. Essas relações são culturais e, neste sentido, as práticas juvenis de conectividade significam formas de integração à cultura urbana contemporânea, intensamente midiatizada. Mas que significados os jovens atribuem à leitura?

Com base em pesquisa recente (QUADROS, 2011), que envolveu garotos e garotas na cidade de Porto Alegre, com o objetivo de compreender as práticas culturais de escuta e de seus pertencimentos a múltiplas redes de sociabilidade na construção de identidades, culturas juvenis e estilos de vida, questionou-se o lugar das práticas de leitura no cotidiano destes jovens.

Outras pesquisas como as desenvolvidas pelo Centro de Leitura e Literatura Infantil e Juvenil - "Maria Betty Coelho" (CELLIJ/UNESP-Presidente Prudente, SP), abordando possíveis articulações entre os atos de ler e literatura para jovens, no âmbito da Educação, têm nos inquietado, nos colocando diante de questões como: quem é este jovem aluno? Quais os marcadores identitários que o distinguem de jovens de outros lugares e tempos? Diante destes questionamentos, a leitura surge como uma possibilidade de reconhecer quem somos e enriquecer nosso conhecimento sobre os outros, sobre outras culturas, tempos

\footnotetext{
${ }^{1}$ As traduções das obras citadas (de originais em língua estrangeira) são de responsabilidade das autoras.
} 
e espaços.

Jobe e Sakari (1999) afirmam que, através da leitura, desenvolvemos nosso repertório cultural e a possibilidade de sentir, reconhecer e compartilhar emoções e pensamentos com outros, de nos colocarmos nos seus lugares. Se a leitura nos permite conhecer e desejar outros e diferentes mundos, é relevante utilizá-la para a formação sensível e intelectual dos jovens. Assim, propomos, neste artigo, caracterizar o perfil do leitor jovem, apresentar e discutir a definição de leitor relutante (Jobe e Sakari, 1999), mostrando como construir práticas de leitura a partir de interesses juvenis, a partir da saga Harry Poter.

\section{Juventude 'inventada' - quem são e como leem o mundo?}

As práticas sociais cotidianas, como a leitura, possibilitam-nos a apropriação da cultura e a expansão de significados. É o compartilhamento dos significados que torna cultural objetos, atitudes e ações (Hall, 1997). Deste modo, como educadores, devemos estar atentos às narrativas produzidas pelos e para os jovens, pois elas ensinam e mostram especificidades da juventude contemporânea. É importante percebermos que, muitas vezes, o jovem adere a determinado estilo ou objeto como um marcador identitário que o diferencia dos demais e, ao mesmo tempo, o vincula a um grupo. As manifestações culturais inscritas no mundo musical, cinematográfico, esportivo ou literário acabam por produzir grupos de indivíduos que frequentam os mesmos lugares, vestem-se de forma semelhante, conversam sobre os mesmos assuntos. Neste sentido, destacamos parte da conversa com o jovem Rodrigo (16 anos) ${ }^{2}$, estudante do ensino médio, na qual ele explica seus diferentes modos de ser, a partir de suas escolhas:

Rodrigo: Sabe, eu sempre acho um pouco difícil estas coisas de me pensar assim ou assado. No ano passado odiava a minha escola. [...] Era sempre uma pegação de pé: "deixa o celular aqui na frente...tu sempre chega atrasado". Pior...era verdade...

\footnotetext{
${ }^{2}$ O excerto de diário de campo de 24 agosto de 2011 é parte da pesquisa referida (Quadros, 2011). A observação em campo ocorreu entre 2007 e 2011. Os jovens que constituíram os sujeitos da pesquisa estão referidos por nomes fictícios com o objetivo de resguardar suas identidades. As idades estão citadas como forma de melhor identificar seus pertencimentos a diferentes grupos etários.
} 
só que eles não podiam reclamar: minhas notas eram boas, as tarefas estavam em dia. Cumpria com a chatice, até estava na escola, tá ligado?!..,Sempre no laboratório de informática baixando música ou jogando. Já jogou o Prisioneiro de Azkaban? Muito massa. Do Harry Potter...é sinistro e a trilha é bem legal. Mas é caro, então a gente faz assim, como com as músicas: um compra e copia para os outros. Depois que comecei, li os livros, um tijoloão, meu! E até vi os filmes. Legal. Agora troquei de bruxo, estou na coleção do Percy Jackson e os Olimpianos, do Rick Riordan, só que este já tá na web para fazer download...pirata, claro.

A narrativa de Rodrigo possibilita (re)conhecer as múltiplas facetas com que se apresentam as identidades juvenis contemporâneas, datadas e localizadas, discutíveis e sujeitas a redefinições, reinterpretações, em diferentes contextos históricos (Velho, 2006). Não existe uma juventude única, mas 'juventudes', pois ainda que os jovens possam estar expostos à interpelação de produções midiáticas quase comuns, a forma como produzem suas identidades está atravessada por traços de classe social, gênero, raça/etnia, marcas do lugar onde vivem, dos grupos etários a que pertencem e da diversidade cultural a que estão expostos.

Nilan e Feixa (2006) reforçam tal argumentação afirmando que, em tempos de globalização, as possibilidades de conexão e informação têm se multiplicado e um fenômeno, aparentemente igual em diversos países, pode adquirir nuances locais que o diferenciam. Um exemplo disso é o que tem ocorrido com a saga Harry Potter. Revendo material de divulgação e matérias jornalísticas dos diferentes períodos de lançamento dos livros, podemos observar características similares e peculiares dos diversos mercados e públicos.

A conversa com Rodrigo dá visibilidade a tais atravessamentos. Seu pertencimento a dada comunidade de leitores-espectadores-internautas pode ser identificado a partir das referências às imagens-modelo colocadas em circulação, cotidianamente. Os personagens-título das obras mencionadas - Harry Potter e Percy Jackson -, as formas de acesso às mesmas e a outras produções tecnológicas e midiáticas nos permitem inferir aspectos das identidades e culturas juvenis a que Rodrigo se filia.

Quando o garoto explicita como ele e seus amigos acessam tais livros ou músicas, anuncia o que é prática do grupo. De acordo com Willis (1990), essas práticas podem ser cruciais para a criação e manutenção de identidades individuais e do próprio grupo, culturalmente. Este autor afirma que o universo da cultura 
da mídia eletrônica - e incluiríamos digital - constitui uma importante fonte simbólica, poderosamente estimulante, quando abordamos o trabalho criativo que a juventude produz, a partir de seus fragmentos. O jovem aprenderia, de forma privilegiada, a reinterpretar códigos, reformatar produtos e mensagens, a partir de seu próprio repertório.

A fala de Nathy (atualmente com 21 anos e estudante de Design de Moda em uma instituição de ensino superior privada) pode nos ajudar a aprofundar esta reflexão:

\begin{abstract}
Nathy: Lá pelos meus 12 ou 13 anos...não sei bem... Eu também gostava muito de ver desenhos na TV ULBRA por que eles passavam o que tinha de mais antigo, mais ingênuo na televisão. Aí eu ia para casa, ver o Dragon Ball $Z$ que eu gostava muito e até me influenciou muito por eu gostar desse desenho para eu desenhar, porque quando eu comecei, eu olhava o desenho, eu desenhava essas coisas de Mangá e isso acabou influenciando as minhas escolhas profissionais: hoje eu faço desenho de moda, né. Por eu gostar de desenho e desenhava, por gostar dessas coisas, eu acabei entrando nessa área, né. É uma estética do desenho japonês, não era o modelo da Xuxa ou outros mais contemporâneos. Eu acho que Dragon Ball Z, Os Simpsons e Bones acabaram sendo uma coisa interessante. Eu gosto basicamente de coisas antigas. ${ }^{3}$
\end{abstract}

A narrativa de Nathy não pode ser classificada em esquemas fixos de compreensão de sua juventude, pois visibiliza um mosaico de elementos, incluindo preferências literárias e midiáticas, além de usos sociais de tecnologias que, articulados, justificam suas escolhas profissionais, experiências escolares, relações entre pares e consciência estética.

Assim, as narrativas de Rodrigo e Nathy nos deixam perceber como eles se fazem integrantes de determinada cultura juvenil. Eles articulam elementos de diferentes temporalidades, produzindo o que Martín-Barbero (2004) caracteriza como destempos ou a convivência do múltiplo, constituída de simultaneidades, na forma de palimpsesto.

Martín-Barbero (2004) ainda ressalta que a maneira do jovem se relacionar

\footnotetext{
${ }^{3} \mathrm{O}$ excerto de diário de campo de 4 de agosto de 2010 é parte da pesquisa desenvolvida por Quadros(2011).
} 
com a tecnologia, as mídias e o consumo cultural é uma espécie de deslocalização, ou seja, um zapping - composto de "restos" de programas, telenovelas, informativos, esportes e espetáculos. Neste sentido, Martín-Barbero (2004) e Yúdice (2007) contextualizam as culturas juvenis e suas práticas na contemporaneidade como integrantes de uma nova experiência cultural constituída por novos modos de perceber e de sentir, de escutar e de ver o outro, o entorno e o mundo.

\section{Livro - tô fora, não leio, odeio}

Diante da contextualização do jovem no mundo contemporâneo, um sujeito vinculado a vários mundos, conectado a diferentes mídias, inserimos a questão: e o livro, esse jovem lê? Os dados estatísticos sobre a qualidade da leitura e sobre o interesse discente pelo livro impresso nas escolas são considerados frustrantes. Diante disso, o fato de uma série de livros de literatura, apoiada em vários suportes midiáticos, alcançar o volume de vendas e circulação, conquistado por Harry Potter, pode ser um bom motivo para examinarmos o fenômeno detalhadamente. Se estes livros foram lidos, manipulados, comentados, gerando narrativas escritas, produzidas por crianças e jovens em idade escolar que conduziram ao prazer pela leitura, merecem a atenção dos pesquisadores de Educação. Não podemos negar que a saga criada por Rowling colaborou na formação de muitos leitores e levou novos consumidores ao mercado livreiro. Contudo, não foram poucos os jovens leitores que resistiram à leitura de Harry Potter, restringindo-se a assistir filmes e a disputar os jogos eletrônicos da série.

Buscando compreender a indiferença dos jovens diante da série ou de outras obras também divulgadas e com recordes de vendas, encontramos, em Jobe e Sakari (1999), a proposta de que se olhe para essa juventude como reluctant readers ou leitores relutantes. Os autores advertem que, ao se procurar compreender as estratégias utilizadas pelos jovens para postergar a leitura, dois aspectos não podem ser negligenciados: eles não são "naturalmente" leitores relutantes, mas diante de determinadas circunstâncias ou fatores, tornam-se relutantes, cabendo aos adultos, principalmente a professores e familiares, identificar os motivos dos adiamentos e as formas adequadas para enfrentá-los.

Um segundo aspecto apontado por Jobe e Sakari (1999) é a necessidade dos 
adultos estarem alertas para os efeitos da preocupação corrente sobre dificuldades e falta de prazer enfrentadas pelos garotos, diante da leitura. Destacam que todos, diante de alguma situação ou tarefa indesejada, produzem estratégias de adiamento. A escola pode ser uma das responsáveis pela relutância dos leitores em formação, principalmente se a leitura estiver acompanhada de prazos e avaliações inadequados, ou não considerar os interesses e preferências individuais ou do grupo de jovens.

São muitas as justificativas destes leitores para o adiamento da leitura: tarefas escolares, esportivas e de lazer. Além dessas "obrigações", existem as brincadeiras com os amigos, os programas de televisão, os jogos on e off line no computador, as redes sociais, baixar e escutar músicas, etc. Diante de tantos compromissos diários, "criar um tempo" para a leitura é a grande questão diante do risco da autodesignação de "não leitores" que, mesmo tendo a capacidade de compreender significados a partir do texto lido, negam-se a ler.

Não é raro ouvirmos afirmações proclamando que mais e mais crianças estão lendo aquém do desejado para o seu nível de escolarização. Entretanto, não só Jobe e Sakari (1999), mas também Cosson (2014) assinalam que pesquisas não sustentam esse ponto de vista sem problematizá-lo. Se é verdade que as práticas de leitura tradicionais têm decrescido, também é verdade que há muitas formas de ler, assim como uma gama de materiais diferentes para ler - não somente livros, mas telas de computadores, sinalização urbana, charges, histórias em quadrinhos, ilustrações, etc. Nossos hábitos de leitura, alertam os estudiosos, mudaram nas últimas décadas. Lemos de maneiras diferentes e a partir de suportes que se multiplicam, promovendo outros níveis de recepção.

Ainda assim, não são estes aspectos que mais mobilizam o interesse dos jovens. Ao perguntar sobre as razões para ler, alguns alunos envolvidos na pesquisa afirmaram que o fazem para descobrir e conhecer como fazer coisas, ter novas experiências; experimentar emoção e aventura; e/ou distanciar-se das questões cotidianas. Na narrativa de Raphael (17 anos), estudante do ensino médio, há indícios de que anteriormente era leitor habitual e, agora, se aproxima do perfil caracterizado como leitor relutante:

Raphael: Sempre tive uma agenda cheia. [...] escola, futebol, aula de piano, fazer as tarefas, mais futebol. Desde que aprendi a ler, os livros eram meus companheiros. Minha mãe brigava comigo porque ficava lendo até muito tarde. No 
dia seguinte, antes de ir à escola, fazia tudo rapidinho e lia até quase me atrasar. Harry Potter era o meu preferido. Eu comprava os livros na pré-venda e recebia no dia do lançamento! Assim que chegava, lia rápido, sem parar. Queria saber como continuava. Na escola, a gente se reunia, trocava uma ideia sobre o que tinha acontecido com os personagens. Às vezes eu não gostava muito do que a autora tinha escrito. Depois, lia de novo devagar para ver os detalhes. Voltava nos livros anteriores, pensava histórias diferentes. [...] Hoje tenho que ler vários livros para a escola, além das leituras para o exame para ir para a universidade. Não estudei sempre aqui. Não li estes livros. Sou muito lento na leitura em português, melhor seria que alguém lesse para mim [ri tímido]. Entendo bem porque minha mãe e meu pai são daqui. Alguns livros consegui os arquivos. Ouço no iPhone enquanto vou para escola. Acho que hoje ele é mais meu parceiro. ${ }^{4}$

Jobe e Sakari (1999) argumentam que, mesmo quando estes jovens reconhecem que há boas razões para ler, não o fazem. Alegam que são leitores muito lentos; estão permanentemente ocupados; ler é algo desinteressante, às vezes; difícil se comparado à televisão. Parte destes argumentos aparece na fala de Raphael e, segundo os autores, quando os jovens afirmam que leem muito lentamente, há sob tal afirmativa a suposição de uma única velocidade de leitura, desconsiderando-se a necessidade de o leitor ser flexível e inferencial, a partir do tipo de material de leitura e da intencionalidade.

Menos presente no contexto escolar e nas culturas juvenis brasileiras está o argumento de que "leitura é coisa de menina..." (para justificar o não interesse pela leitura). Nos contextos observados, jovens de ambos os sexos leem ou não leem. As únicas referências dizem respeito apenas aos hábitos familiares, como comenta Camila, 14 anos, estudante do ensino fundamental:

Camila: Lá em casa ninguém lê muito, mas eles tão sempre de bronca comigo para ler os livros da escola. Eu não gosto de livro, nunca vi meu pai e minha mãe comprarem livros. [...] Por que tenho que ler se já ouvi meu pai dizer que aprende mais sobre História com os filmes do que aprendeu nos livros da escola? ${ }^{5}$

\footnotetext{
${ }^{4} \mathrm{O}$ excerto de diário de campo de 15 de junho de 2011 é parte da pesquisa desenvolvida por Quadros(2011).

${ }^{5} \mathrm{O}$ excerto de diário de campo de 21 jul. 2011 é parte da pesquisa desenvolvida por Quadros (2011).
} 
Se, de um lado, temos leitores muito ocupados, receosos da desconexão e suas consequentes 'perdas' relativas aos seus grupos de pertencimento on e off line; de outro, Camila e Raphael corroboram o fato dos adultos subestimarem a importância de serem modelos para os mais jovens, restringindo-se ao discurso sobre a importância da leitura.

Caracterizando os leitores relutantes, Jobe e Sakari (1999) argumentam que eles têm o conhecimento do que precisam para se tornarem leitores competentes, mas não o utilizam, em razão do medo de falhar. Leitores relutantes não creem que possam ler, veem a si mesmos como não-leitores.

A partir de pesquisa desenvolvida com estudantes canadenses, Jobe e Sakari (1999) classificam a maioria dos leitores relutantes em quatro grupos principais: "Eu não posso"; "Eu não sei como"; "Eu prefiro" e "Eu não me importo". Os leitores do grupo "Eu não posso" são caracterizados como passivos, especialistas em evasão e pelo medo de correr riscos e falharem. Já os "Eu não sei como" apresentam outras características que os levam a evitar a leitura. Geralmente, se frustram com facilidade e não se responsabilizam por tarefas inerentes à sua aprendizagem. Colocam-se numa posição de dependência do professor/adulto e esperam que este forneça respostas/soluções diante da sua passividade.

Uma terceira denominação é aplicada por Jobe e Sakari (1999) aos leitores relutantes que se caracterizam por ter sua atenção voltada para objetos e processos de manufatura, além de serem interessados no que se refere ao "mundo real". Os leitores relutantes do grupo "Eu prefiro" estão constantemente buscando informações, são ativos e gostam de fazer "descobertas", dissertando sobre elas com detalhes. Leem com avidez vários tipos de materiais, mas se mantêm focados exclusivamente em assuntos de seu interesse. Sobre qualquer outro tópico, sua atenção se desvia constantemente. Neste sentido, percebe-se o quanto a escola não consegue capturá-los para a leitura.

Jobe e Sakari (1999) abordam, ainda, o denominado leitor relutante "Eu não me importo", como aquele que apresenta sucessivas falhas no processo de letramento e afirma não poder e não querer ler. Tais leitores, comumente, são mais velhos que os demais, têm um histórico de insucessos e mostram-se desinteressados. Não conseguem perceber o valor social, cultural e, algumas vezes, econômico, que o letramento pode ter como exigência das sociedades ocidentais para o acesso a bens culturais e materiais e ao mundo do trabalho. 
Algumas questões relativas à estruturação do currículo e à regulação do tempo (pouco flexíveis) precisam ser repensadas na escola, pois, habitualmente, segundo Jobe e Sakari (1999), ela falha com estes leitores em formação, levando-os a não perceberem o valor da leitura.

Pensando os leitores relutantes e suas práticas, os pesquisadores alertam que se considere, acima de tudo, os interesses dos mesmos como estratégia para construir o processo de letramento. Identificá-los demanda dos professores o posicionamento constante de observador/ouvinte em todos os ambientes da escola. Exige, também, que o professor esteja atento aos possíveis obstáculos que possam estar presentes no processo. Dito de outra forma, as crenças que os leitores relutantes têm a respeito de si mesmos e a respeito da leitura, assim como o currículo e a regulação do tempo escolar podem apresentar-se como aspectos que dificultam a superação da relutância, da ansiedade e do medo de falhar que caracterizam estes jovens.

Se refletirmos sobre os aspectos que abordamos até aqui, caracterizando o jovem leitor relativamente à sua relutância, é possível afirmar que o poder da leitura (de ficção) reside no fato de lhe permitir que se saia de si mesmo, que tenha acesso ao pensamento, reflexão e imaginação anteriormente não experimentados.

Neste sentido, ponderando sobre o que ouvimos destes garotos sobre suas práticas de leitura, articuladas com os vários recursos da cultura contemporânea, utilizaremos a seguir, como sugestão para descoberta do prazer de ler, no processo de formação do jovem leitor, a série Harry Poter.

\section{Leitores Relutantes: aprendendo o prazer de ler, com Harry Potter}

Desde o lançamento de Harry Potter e a pedra filosofal ${ }^{6}$, em 1997, na Inglaterra, as histórias do pequeno bruxo, sua escola, amigos e professores, vinham sendo "objeto de desejo" de milhões de crianças e jovens em todo o mundo.

\footnotetext{
${ }^{6}$ Os sete livros da série foram publicados no Brasil através da Editora Rocco: Harry Potter e a pedra filosofal (2000); Harry Potter e a câmara secreta (2000), Harry Potter e o prisioneiro de Azkaban (2000), Harry Potter e o cálice de fogo (2001), Harry Potter e a Ordem da Fênix (2003), Harry Potter e o enigma do príncipe (2005) e Harry Potter e as Relíquias da Morte (2007). A série foi adaptada para cinema em oito filmes produzidos pela Warner/UK/USA.
} 
Igualmente eram "objeto de ódio" de críticos que viam, na série, apenas mais um best-seller em razão das estratégias adotadas pelo mercado editorial em nível global (Borelli, 2010). Analistas comentavam que, a partir de sua chegada às livrarias - a obra foi quase imediatamente traduzida para 35 idiomas e distribuída em 200 países -, pesquisas mostravam que a leitura entre os jovens de 10 a 19 anos havia crescido 19\%, e não se restringia às histórias do pequeno bruxo (Hallett, 2005).

No Brasil, a obra foi editada em 2000 e, assim como em outros contextos, as escolas se tornaram o local de encontro dos jovens leitores que passavam a se organizar num misto de fã-clubes e clubes de leitura on e off line para discutir, recontar e reescrever as histórias de Harry.

Vários autores e pesquisadores buscaram refletir sobre a obra em meio à polêmica. Uma questão ressaltada nas discussões era o descompromisso com a "literariedade dos textos" (Rösing, 2005). Outro aspecto abordado por Coelho (2005), Samdja (2004) e Appelbaum (2003) sobre Harry Potter relaciona-se mais diretamente ao foco temático deste texto: quais as razões para o enfeitiçamento que transformava jovens não-leitores em leitores habituais? O termo "enfeitiçamento" é usado pelos três autores para enfatizar a rápida mudança nas práticas de leitura e crenças sobre si mesmos, a partir das preferências e interesses individuais dos jovens, apoiados em seus grupos de pertencimento. Como destaca Coelho (2005), a mobilização dos leitores parecia ir na contramão das tendências verificadas nas práticas de leitura contemporâneas, marcadas por múltiplas visualidades, presença da internet, velocidade e quantidade crescente de informação, como também no suposto afastamento do livro da sua própria forma clássica. A série criada por Rowling era composta por obras com centenas de páginas, sem ilustrações, textos com frases longas e nomes difíceis, e uma trama que se complexificava a cada novo volume.

Samdja (2004) e Appelbaum (2003) abordaram o fenômeno sob outro viés. Apostava-se que o sucesso dos livros estava ligado às múltiplas camadas superpostas de possíveis leituras. Estas características remeteriam aos contos, lendas, mitologias e acontecimentos atuais, revestidos de humor e imaginação, possibilitando perceber a saga como um conto de fadas moderno. Para Appelbaum (2003), a obra trabalhava conflitos gerados pelo duplo enquadramento dos jovens (problemas e soluções), elemento provocador e de interesse dos leitores.

Jobe e Sakari (1999), refletindo sobre as mudanças a serem operadas nos lei- 
tores relutantes para se transformarem em leitores habituais, destacam que algumas estratégias, materiais de leitura e métodos de ensino funcionam melhor do que outros. Os autores apontam que o envolvimento físico através da manipulação; resolução de problemas, quebra-cabeças e livros de jogos podem ser eficientes para provocar o envolvimento mental, sem uma relação direta com o risco de o leitor falhar no processo de leitura. Muitos dos produtos licenciados por Rowling, com a marca Harry Potter, parecem ter cumprido este papel. Varinhas mágicas e jogos que envolviam noções básicas de química fizeram com que meninos desinteressados recorressem aos livros para reconhecer nomes de feitiços que ativavam, por voz, mecanismos sonoros e luminosos das varinhas, ou (re)conhecessem efeitos possíveis de fórmulas e poções que fizessem ferver tubos de ensaio ou trocar (temporariamente) a cor de cabelos.

A escolha de livros que mobilizem o interesse pessoal dos leitores, utilização de materiais baseados na "vida real" e a elaboração de novas regras para jogos já existentes são apontadas pelos autores como estratégias adequadas para lidar com leitores que se enquadram nos perfis relutantes: "Eu não sei como" e "Eu prefiro". Elas podem ajudá-los a lidar e a vencer o medo. A invenção do Quadribol de Trouxas pode ser tomada como uma possibilidade. Fãs de Harry Potter reúnem-se para colocar em prática o jogo fictício adaptado.

A própria divisão da narrativa em sete volumes, descrevendo relações e acontecimentos fantásticos ocorridos durante sete anos de vida (escolar) de crianças e jovens, aproximou os leitores do livro/produto. Harry Potter foi concebido como obra de ficção seriada, formato já conhecido dos leitores.

Pensando nos leitores relutantes, Jobe e Sakari (1999) apontam os livros em série como uma das interfaces amigáveis de entrada destes jovens em formação no mundo da leitura. Argumentam que quem gosta de um livro tende a gostar dos demais como uma espécie de reencontro seguro com personagens que sabem quem são e como vão (re)agir, lhes proporcionando uma espécie de conexão emocional. A familiaridade com o estilo seriado diminui riscos, pois cada edição obedece o padrão estabelecido no volume de estreia. "O vocabulário, a ação, e os personagens são basicamente os mesmos a cada livro. Um leitor relutante, em particular, não tem que despender energia em descobrir novos personagens; a luta para ler é facilitada" (Jobe e Sakari,1999, p.86).

Apesar de todo o amplo e sofisticado processo de comercialização de Harry Potter, como produto e cultura (projeto editorial estratégico de construção das 
capas, utilização de sites oficiais das obras, adaptação para o cinema, criação de ambientes produzidos à semelhança dos cenários da trama na forma de livros pop up ou parques temáticos), a série não pode ser tomada somente como um fenômeno mercadológico. Através do interesse despertado, inúmeros leitores aderiram à leitura a partir de diferentes percursos possibilitados pelo contexto multimidiático.

Neste novo contexto de leitores e leituras, constatamos que a leitura silenciosa, individual, em tempos e lugares próprios é, ainda, uma das formas mais usuais desta prática; mas formas coletivas e em ambientes antes não considerados têm sido verificadas e indicadas, a fim de capturar diferentes perfis de leitores. Tal flexibilidade está ligada não somente às várias mídias em incessante reinvenção, a partir do computador e da internet; também se destacam as mudanças sofridas pelo livro como suporte, ao longo do tempo. Harry Potter está disponível numa multiplicidade de suportes: do livro tradicional e brinquedos até jogos de computador (Borelli, 2010).

Naquilo que se busca analisar, neste artigo, ou seja, a mobilização do interesse de jovens leitores quanto às práticas de leitura, há, ainda, uma complexidade adicional: a possibilidade de utilização de suportes digitais, que transformou leitores/consumidores em leitores/produtores. Não foram poucos os jovens que, diante dos recursos oferecidos pela internet, passaram a 'colaborar' emocional e intelectualmente com o texto, como parte do processo de fruição e criação (reescrita).

Este tipo de prática aproximou os leitores de Harry Potter do processo de (re) produção da trama: em revistas, blogs, sites, e redes sociais. Jovens, habitualmente distantes do livro e da leitura, ao tecerem hipóteses, construindo inferências para preencherem as lacunas deixadas pelos textos, rompem com o perfil de leitor relutante e passam a frequentar o mundo dos livros.

Apoiadas nas ideias de Jobe e Sakari (1999) e no cenário que construímos aqui neste texto, concluímos haver possibilidade de mudarmos as crenças dos leitores relutantes sobre eles mesmos e, assim, transformar suas habilidades de leitura. Os autores indicam que obras consideradas "legais" pelos pares podem ser um caminho, assim como o diálogo do livro com outros materiais indicados pelos integrantes do grupo de convivência do jovem leitor tais como: músicas ou material em circulação nas redes sociais. Computadores e internet, assim como outros materiais usados no cotidiano também são interfaces amigáveis de 
entrada no mundo da leitura. Os leitores relutantes têm medo de correr riscos, alegam que o material de leitura é muito difícil. Estabelecer uma conexão entre a experiência cotidiana dos jovens e o processo gradual de entrada no universo do livro é missão social da escola.

Neste sentido, o sucesso do educador/mediador com os leitores (relutantes) implica vê-los como detentores de diferentes capacidades para a leitura. Prestar atenção às necessidades dos jovens e incluir seus interesses no currículo, podem auxiliar a escola a atrair os leitores relutantes para o prazer da leitura.

\section{Referências Bibliográficas}

APPELBAUM, Peter. Harry Potter's World: Magic, Technoculture, and becoming human. In: HEILMAN, E. E. Ed. Harry Potters's World: multidisciplinary critical perspectives. New York: London: Routledge Falmer, 2003. pp. 25-51.

BORELLI, Silvia H.S. Campo editorial e mercado: a série Harry Potter. In: BRAGANÇA, A; ABREU, M Org(s). Impresso no Brasil: dois séculos de livros brasileiros. São Paulo: Editora Unesp, 2010. pp. 381-398.

COELHO, Nelly N. O fenômeno Harry Potter e o nosso tempo em mutação. In: JACOBY, S; ROTTENMAIER, M. Org(s). Além da plataforma nove e meia: pensando o fenômeno Harry Potter. Passo Fundo, RS: UPF, 2005. pp. 53-66.

COSSON, Rildo. Círculos de leitura e letramento literário. São Paulo: Contexto, 2014.

HALL, Stuart. The Work of Representation. In: HALL, S. Org(s). Representation. Cultural Representations and Signifying Practices. London: Thousand Oaks: New Delhi: Sage, Open University, 1997.

HALLETT, V. The power of Potter - can the teenage wizard turn a generation of halfhearted readers into lifelong bookworms? in: U.S. News \& World Report, New York, n.3, vol. 139, p. 44-51 July 25, 2005.

JOBE, Ron; SAKARI, Mary Dayton. Reluctant Readers: connecting students and books for successful reading experience. Ontario: Pembroke Publishers, 1999.

MARTÍN-BARBERO, Jesús. Ofício de cartógrafo: travessias latino-americanas da comunicação na cultura. São Paulo: Loyola, 2004.

NILAN, Pam; FEIXA, Carles. Ed(s). Global Youth?: hybrid identities, plural worlds. London: New York: Routledge, 2006.

QUADROS, Marta Campos de. Tá Ligado?!: Práticas de escuta de jovens urbanos contemporâneos e panoramas sonoros na metrópole, uma pauta para a Educação. Tese (Doutorado em Educação) - Universidade Federal do Rio Grande do Sul. Porto Alegre, 
2011.

RÖSING, Tania. Uma reflexão necessária. In: JACOBY, S; ROTTENMAIER, M. Org(s). Além da plataforma nove e meia: pensando o fenômeno Harry Potter. Passo Fundo, RS: UPF, 2005. pp. 07-10.

SAMDJA, Isabelle. Harry Potter: as razões do sucesso. Rio de Janeiro: Contraponto, 2004. VELHO, Gilberto. Juventudes, projetos e trajetórias na sociedade contemporânea. In: ALMEIDA, M. I. M. de; EUGÊNIO, F. Org(s). Culturas Jovens: novos mapas do afeto. Rio de Janeiro: Jorge Zahar, 2006. pp. 192-200.

WILLIS, Paul. Common Culture: symbolic work at play in the everyday cultures of the young. Buckingham, UK: Open University Press, 1990.

YÚDICE, George. Nuevas Tecnologias, Música y Experiência. Barcelona: Gedisa, 2007. 